\title{
Telepresence and Trust: a Speech-Act Theory of Mediated Communication
}

\author{
Thomas W. Simpson ${ }^{1}$
}

Received: 29 January 2016 / Accepted: 19 August 2016 / Published online: 19 September 2016

(C) The Author(s) 2016. This article is published with open access at Springerlink.com

\begin{abstract}
Trust is central to our social lives in both epistemic and practical ways. Often, it is rational only given evidence for trustworthiness, and with that evidence is made available by communication. New technologies are changing our practices of communication, enabling increasing rich and diverse ways of 'being there', but at a distance. This paper asks: how does telepresent communication support evidenceconstrained trust? In answering it, I reply to the leading pessimists about the possibility of the digital mediation of trust, Philip Pettit and Hubert Dreyfus. I also rebut Media Richness Theory, which proposes a linear relationship between the volume of mediated information and the quality of communication. Positively, I develop a speech-act theory of digitally mediated communication, drawing on Austen's identification of the illocutionary act. The choice of a particular technology of communication constitutes part of what is communicated, including a setting of the social 'frame', and thus the possibilities for trust to be sustained or eroded. How something is said is part of what it is that is said.
\end{abstract}

Keywords computer-mediated communication $\cdot$ Dreyfus $\cdot$ evidence $\cdot$ media richness theory $\cdot$ Pettit $\cdot$ speech-act theory $\cdot$ telepresence $\cdot$ trust

\section{Introduction}

Trust is central to our lives in both epistemic and practical ways. We know by trusting what others tell us. We act on the basis of knowledge acquired by trust, and on the basis of trust in others' commitments. In paradigm cases, epistemic and practical trust is based on communication. Others tell us that $p$ or promise to $\varphi$, and this act of communication grounds our trust. Often enough, both epistemic and practical trust

Thomas W. Simpson

thomas.simpson@bsg.ox.ac.uk

1 Blavatnik School of Government, Radcliffe Observatory Quarter, Woodstock Road, Oxford OX2 6GG, UK 
seeks to be well grounded, that is, it is a condition on its being rational that there is sufficient evidence for trustworthiness. Call this evidence-constrained trust.

New technologies are changing our practices of communication. The Internet illustrates this most dramatically. As a general-purpose technology, it enables myriad forms of digitally mediated communication: from e-mail, bulletin boards, Facebook, and Pinterest to WhatsApp, Instagram or Skype. These enable different forms of telepresence, where we are present to others but at a distance (Gk. tēle-, 'far-off'). The speed of development of new forms of telepresent communication is unlikely to slow. Given the significance of both interpersonal trust, its rational dependence on evidence, and the pervasiveness of digitally mediated communication, the question this paper addresses is: How does telepresent communication support evidence-constrained trust? More fully, can it do so by providing evidence that is able to support a robust judgement about another's trustworthiness?

There are two influential positions I will rebut in answering. The first is pessimism about digitally mediated trust, which denies that trust may rationally be sustained through online communication. My question implies that telepresent communication can support evidence-constrained trust. Not only is this a possibility, I will endorse its actuality. The second position is influential not so much among those who reflect on the philosophical significance of new technologies, but with those who design and build them. For that reason, it is perhaps the more significant. In a slogan, the view is 'more is more': the greater the approximation to face-to-face interaction at either end, the better the communication. The natural conclusion from this view is that evidence-constrained trust will be better supported the closer the mediating technology affords an experience akin to offline communication. The basic idea is so intuitive that it has pull much beyond those influenced by its explicit articulation in Media Richness Theory. While not without merit, it requires significant qualification.

The positive thesis I argue for is as follows. Properties of specific digital technologies make them more or less apt for particular communicative acts. This is the degree that they shape what kinds of communicative act are possible. How something is said is part of what it is that is said. In J. L. Austin's terms, the choice of communicative technology is part of the illocutionary dimension of the speech-act. And as apt communication is a significant indicator of trustworthiness, and sometimes the determinative such indicator, evidenceconstrained trust will often be rational only given a choice of mediating technology that demonstrates understanding of the communicative encounter. The communicative potential of telepresent technologies is thus substantially affected by the norms that have developed, and will develop, around each of its forms. In terms of the degree of 'presence' enabled by the technology and the quality of communication, sometimes, less is more.

The structure of the paper is as follows. I first identify a trajectory of development of telepresent technologies (Sect. 2). The interrelations between trust, evidence and practices of communication then follow. This draws on recent work on trust and the epistemology of testimony and provides a theoretical frame for the applied discussion (Sect. 3). I then reply to the two leading cases for pessimism about digitally mediated trust, namely those by Philip Pettit and Hubert Dreyfus, developing my argument by drawing on empirical studies of how telepresent communication is experienced (Sects. 4 and 5). This is the basis for the positive task of developing a speech-act theory of mediated communication (Sect. 6). The scope of my argument is noted in conclusion (Sect. 7). 


\section{Telepresence}

Marvin Minsky first brought the term 'telepresence' to popular attention. Writing in a science fiction magazine, he was concerned with technological ways to alleviate the downsides of modern living. In particular, he identified that conjoining remote perception with remote action might bring benefits across a diverse variety of applications, given instruments that 'feel and work so much like our own hands that we won't notice any significant difference' (1980: 47). Prompted by Three Mile Island, his paradigm case was of an accident at a nuclear power plant, where remotely operated systems would allow extended operation in conditions that are otherwise lethal for people, so replacing humans. Other envisaged areas of application were: waste processing; land and sea mining; a globalised market for manual labour; new medical and surgical techniques; remote working leading to a reduction in commuting; and low-cost space stations. He identified the ARPANET, the Internet's precursor, as a tool through which remote perception and action could be conducted. Minsky thought that with a relatively modest investment of research time and effort, on the order of $\$ 1$ billion, it would take only 10 to 20 years to develop the systems capable of these tasks.

As Fukushima testifies, Minsky's time estimate on the redundancy of human manual labour was optimistic. ${ }^{1}$ But his fundamental vision is now much closer to fulfilment, and discussions of it are no longer the exclusive remit of science fiction magazines. This is possible as a result of extensive research on the two dimensions of his proposal: both remote perception and remote action. I comment on these in turn.

The mediation of presence, through two-way remote perception, has been the core function of telephone companies since Graham Bell's invention. The quality of telephony varies in three dimensions: the accuracy with which sound is reproduced, the speed of transmission and the capacity for two-way rather than one-way communication. Summarise the degree to which face-to-face presence is replicated as the fidelity of mediation. To illustrate, consider push-to-talk analogue radio transceivers. They allow for one-way communication only, in which one person speaks and the other listens, and this often at a delay and with distortion. Conventional 'landline' calls in the same town suffer from none of these defects. A threshold case occurs when the technology is perceptually erased, such that participants to a conversation do not perceive the mediating technology in how they speak, and the way they comport themselves conversationally is then unaffected by the technology. ${ }^{2}$ So telepresence comes in degrees, according to the degree with which one's presence is mediated.

The telephone yields presence at a distance through one sense modality only, namely sound. But much communication is non-verbal, occurring through body language, for

\footnotetext{
${ }^{1}$ Robots were used at the Fukushima Daiichi plant for immediate emergency response and for longer term cleanup, but this was in addition to the engineers who entered the plant. See $<\mathrm{http} / / /$ spectrum.ieee. org/slideshow/robotics/industrial-robots/meet-the-robots-of-fukushima-daiichi>.

${ }^{2}$ Theorists of presence often identify its occurrence with one's being unaware of the medium that enables the perception or action (see Lombard and Jones 2006). This psychological state is not my concern, for such 'flow' states can be achieved through skilled operation of a tool that nonetheless imposes crude distortions on the quality of perception, communication or action. Luciano Floridi rightly points out that defining telepresence by this psychological phenomenon perversely results in the person who is aware of the mediating technology then not being telepresent, which is plainly absurd (2005: 43). Instead, I am concerned with the degree to which one's perception or action possesses the fidelity of non-mediated and embodied perception and action.
} 
instance. A complementary research programme has thus been into extending the sensory modalities that can be supported telepresently, with the dominant effort into making sight available, through video. Pioneers in the development here were the Xerox PARC and EuroPARC research labs in the 1980s. Primarily aiming to improve the efficiency of their internal working practices, each workspace in the labs was made permanently available to all others, through a video display screen, and the ability to toggle the display to whichever workspace was chosen. Substantial fruits from this and related endeavours are already widely available, most notably in terms of low-cost applications such as Skype and FaceTime. ${ }^{3}$ Improving the quality and synchronisation of the sound and video links has been an enduring project. Another challenge that is proving surprisingly difficult to overcome is the difficulty of making eye contact. Because cameras are offset from the screen that displays the other person, I have a choice to look either at the camera or at the image of my conversation partner. The problem can be partially overcome by sitting some distance from the camera and screen, but this correspondingly increases the sense of separation. While it is a 'mere' technical problem, the difficulty of eye contact introduces a level of friction in telepresent communication that is not experienced when talking face-to-face. The consequences of such problems are significant and have severely limited how widely the technology has been adopted (see Hirsh et al. 2005 for discussion; Sellen 1992, 1995 documents how conversational practices change to accommodate these problems). Nevertheless, rather than the mere 'what' of communication delivered by words alone by a telegraph or suspended on the World Wide Web, telepresence promises also to deliver the 'how'.

Remote action is the aim of a research programme of comparable size and import to that aimed at remote presence. An early artistic installation to explore this possibility was Ken Goldberg and Joseph Santarromana's Telegarden, in the mid-1990s. A robotic arm stood in the centre of a circular compost bed. 'Community members', who agreed to share their email addresses so that the community could be self-governing, were able to control the arm so that it planted seeds and watered the plants. Anyone who wished could watch what was going on. ${ }^{4}$ The development of robotics has been a multi-faceted engineering endeavour, and the results of it have now exploded into popular consciousness, most obviously with systems such as the US Air Force PREDATOR drone and NASA's Mars Explorer Rover. Private adoption of robotic technology is most evident in the growing use of quadcopters. The inaugural 'US National Drone Racing Championships' took place in 2015. Novel applications for the technology will continue apace, from filming wildlife documentaries to baiting football fans with the flag of their nationalist rival, to enabling builders to check a roof without ladders and to conducting forestry surveys. ${ }^{5}$ Automated cars, of course, are in the trial stage. Exoskeletons will take longer, whether with the operator inside or in a remote command module. Remote surgery is another future application.

Where does this trajectory of development culminate? It is largely speculation what precise shape telepresent forms of interaction and communication will take, so what I say

\footnotetext{
${ }^{3}$ For background, see the papers collected in Harrison (2009). For discussion of the controversial anthropological assumptions shared in this research community, see Harper (2009, 2010: 59-108).

4 See <http://goldberg.berkeley.edu/garden/Ars/> and <http://www.usc.edu/dept/garden/>; also papers collected in Goldberg (2000). Dreyfus (2001) alerted me to the Telegarden.

${ }^{5}$ Respectively: <http://dronenationals.com>, <https://www.youtube.com/watch?v=9ImK-P_1mtE >, $<$ http://www.hometownroofingcontractors.com/blog/drones-invade-the-roofing-industry-for-good-not-evil> and $<$ https://novadrone.com/news/drones-for-forestry-mapping/>.
} 
here is an imaginative exploration of possibilities, not a prediction. In terms of enabling remote action, a threshold case occurs when one's remote instrument for moving the world does so with the same precision as one's hands. Other technologies will pass this threshold by enhancing your motor powers, giving either greater precision of action or greater power than flesh and blood is capable of (or both). In terms of remote perception, the threshold case of 'erasure' of mediation has been identified. There is no reason why remote perception could not magnify your perceptual sensitivity beyond that possible with nature. More imaginatively still, why should the senses of sight and hearing only be mediated? Achieving remote fidelity of action comparable to that we have with our hands will all but certainly require a sensitivity of touch that passes the threshold of erasure. Haptic technology is developing in this direction. More ambitious still will be enabling the senses of smell and taste. James Cameron's 2009 film Avatar is a fictional exploration of the full range of possibilities, in which the operator's phenomenological experience is of being embodied in his avatar. In the story, the paraplegic Marine is then able to leave his disability behind. Quite how far along this trajectory future technologies take us remains to be seen. What is certain is that there will be developments in the directions identified above, clunky at first and with more sophistication in time. Consider the 'Double 2'. It is, essentially, an iPad on a stick, on wheels. ${ }^{6}$ It is advertised as giving you a physical presence in the office while you work remotely. Controlling the Double 2 from your keyboard at home, you can drive around the office, dropping in for casual chats on colleagues. While telepresent technologies will enable more than communication, that will be one of their core functions and certainly so for the short to medium term.

I now consider the role that communication plays in supporting rational trust.

\section{Trust and Evidence}

When does trust seek to be well grounded - that is, be based on evidence for trustworthiness? It is nearly an unquestioned assumption in prior philosophical work that trust, in some important sense, goes beyond the evidence. 'One does not actually trust someone to do something if one only believes they will do it when one has evidence that they will' (Faulkner 2007: 876; Baker 1987:1; McGeer 2008: 240). The claim is true for many paradigm instances of trust. These include cases where the trustor commits herself to the trusted, in ways that are supported neither by the evidence for his trustworthiness specifically, nor by evidence of the kinds of behaviour one may expect from people generally in this sort of situation. Consider the silver given by Bishop Myriel to the escaped convict Jean Valjean at the outset of Les Misérables, on the promise that Valjean would use it to become an honest man (Hugo 1862: II, 12). Given against all the evidence, Myriel's act of supererogatory grace casts its beneficent shadow through the novel. But are all instances of trust 'beyond the evidence'? The scope of the conclusion that such cases licence on this question should be carefully noted. No general conclusion can be drawn about the relation between trust and evidence unless the following premise is granted: 'trust' is univocal and always has the same referent.

I deny this. Listening to the way the word is used provides a compressed argument. Sometimes trust is naturally understood as referring to a sort of affective attitude ('I will trust

\footnotetext{
${ }^{6}<\mathrm{http} / / /$ www.doublerobotics.com $>$.
} 
my wife; I will not be jealous'); at other times to a conative one ('Come what may, I will trust you to the end'); and at yet others to cognitive ones ('I know you are honourable; I trust you'). Surely correctly, Annette Baier comments that 'Trust, if it is any of these [affective, cognitive and conative], it is all three' (1994: 132). Indeed, sometimes it is not a mental state but action itself which is described as trust ('The patrol followed the scout, trusting him to spot an ambush before it was too late'). There are surely other uses too. I argue for these claims and give a genealogical explanation for them, at length elsewhere (Author 2012a).

The plurality of forms of trust allows that, on other occasions, trust is appropriate only if, given one's total evidence, it is likely that the trusted will be trustworthy. As an example, consider what it is to invite a teenager to babysit. The first consideration, which must be satisfied, is whether they will be trustworthy: be caring towards your children, sufficiently competent to know what to do in the range of possible scenarios that could occur and so forth. Only once you are assured of this should other factors be considered, such as whether you want to support them with some pocket money or want to give them a decent excuse for an evening away from their parents. To include these factors in your deliberation, but without their having met the standard of trustworthiness, is to fail in your obligations to your children. On such an occasion, one's trust is evidentially constrained.

There are a variety of reasons for why trust is sometimes evidentially constrained. The babysitter example highlights the practical obligations that may result in trustworthiness being required. Other fiduciary relationships also have this structure: public officials have an obligation to grant contracts and to enter trusting partnerships more generally, only when there is assurance of performance, given their obligations to the taxpayer. So too for managers in the private sector, who act on behalf of a company's owners. Sometimes a putative trustor has a practical permission to be concerned for fulfilment of the trust. Consider the norms of trust in the marketplace. In employment, for instance, while contract provides a baseline of protection for both parties, it cannot eliminate the residual and often thick level of trust that goes both ways between employer and employee. Nor is it clear that we should want it to. While an employer may take someone on because they want to do them a good turn, the more usual situation, and which is undoubtedly permissible, is for employers to take someone on only when they have good evidence for their trustworthiness. So practical reasons may give either a permission or an obligation for one's trust to be evidentially constrained.

Epistemic reasons generate an obligation for one's trust to be evidentially constrained. In instances of testimony, where a hearer is invited to trust a speaker for the truth of what she attests, one should do so only given sufficient probability, on one's total evidence, of her truthfulness, that is, of her trustworthiness. This is because belief aims at the truth. Insofar as anything counts as evidence for $p$ only if it raises the probability of $p$, so anything which is evidence should be weighed in one's judgement as to whether $p .^{7}$

Communication is central to enabling trust in two ways. Implicit in the foregoing has been that trust is a tripartite relation, relating a trustor, to someone trusted, regarding some action that the trusted will perform. Schematically, $A$ trusts $B$ to $\varphi$. In the standard

\footnotetext{
${ }^{7}$ I defend the above claims of Sect. 3 at length in Author (Forthcoming). I also reply there to some views about trust and testimonially based belief, which are now current and which I have here presumed to be false, namely 'cognitive non-evidentialism'. This takes trust to be a genuinely cognitive attitude, usually a belief, and as such to be based on evidence. But it is based on a sub-set of the evidence rather than one's total evidence, with that sub-set being delineated on the basis of non-evidentialist reasons, such as one's being a friend with the speaker. Instances of the view include Hurka (2001), Stroud (2006), Hieronymi (2008), McMyler (2011) and Marušić (2015).
} 
case, the $\varphi$ with respect to which $B$ is trusted is identified by communication - through speech, or writing. In such, we may explicitly promise to do something. Often enough, we undertake commitments through conversational practices that leave it understood. This is so in standard cases of assertion, where we assert that $p$. In asserting $p$, we undertake the commitment not to lie, even though we have not explicitly promised to; this commitment is the ' $\varphi$ ' in epistemic trust, and which results in belief that $p$. So identifying the $\varphi$ over which $B$ is trusted is the first way in which trust is essentially enabled by communication. The second way is more variable. When one has the good fortune to live in a society where most are trustworthy, a person's committing to $\varphi$ is usually decisive grounds for believing that they will $\varphi$. In other words, their act of communication is evidence, and evidence that suffices for rational trust. Of course, this may be overridden by other evidence that this particular person is untrustworthy. But in the standard case, 'she said so' is sufficient to justify one's trust (Adler 2002: 147ff.; Author 2012b). ${ }^{8}$ By contrast, in societies or subcultures where most people cannot be trusted, her saying-so is not sufficient. Rather, evidence for the trustworthiness of a particular person is required for trust to be rational. ${ }^{9}$

How does the foregoing relate to digitally mediated communication? Part of the power of the Internet is that it makes communication possible between people who already know each other, but who are not co-located physically, with an ease that is unprecedented. But its greater significance, I suggest, is that it enables communication between people who have never encountered each other offline, and often enough, never realistically could. Call people with whom one has no offline connection, pure virtuals. When interacting with pure virtuals, the obligations I owe them are only those that I owe a person qua person. One's trust is permissibly constrained by the evidence, and one thus rationally seeks evidence of trustworthiness. Given this, I now turn to address the role of telepresence in supporting mediated, rational trust.

\section{Pessimism About Digitally Mediated Trust}

Telepresent communication is significant because it promises to restore, in one key respect, the possibility of judgements of trustworthiness that previously relied on physical co-presence. ${ }^{10}$ Pessimism about digitally mediated trust denies that it is possible for it to be

\footnotetext{
${ }^{8}$ Richard Moran argues that it is a misunderstanding of the act of telling for a hearer to construe it as evidence and that to do so 'puts speaker and audience into disharmony with each other' (2006: 301). His argument is more general, applying also to evidential construals of promises. A full rebuttal is beyond present scope, but to forestall objection, it should be noted that his claims are not in formal conflict with mine. We use different notions of evidence. On his narrow view, evidence consists of things that have (Gricean) 'natural' meaning only and acts or states of affairs with intentional, non-natural meaning, do not. On my broader use, anything that increases the probability of $p$ counts as evidence for $p$, including acts or states of affairs with non-natural meaning. See Kelly (2008: 627) for distinction.

9 The identification of trust as a three-place relation is standard; e.g. Good (1988: 33) and Holton (1994). Recent proposals identifying two-place trust, where $A$ trusts $B$ simpliciter, and which is taken to ground threeplace trust, do not challenge the dependence of rational trust on communication. In all but research cases, it is a history of shared relationship that sustains two-place trust, and communication is essential not only to building such relationships but also to constituting them. For proposals, see Faulkner (2015) and Domenicucci and Holton (Forthcoming).

${ }^{10}$ Better evidence as to whether someone is trustworthy does not imply that there will be more evidenceconstrained trust. For where there are high levels of untrustworthiness, more evidence will, other things equal, lead to less evidence-constrained trust. My focus is only the first stage, the determination of trustworthiness by telepresent forms of communication. I am grateful to an anonymous reviewer for pressing the distinction.
} 
rational. This is the first influential view that this paper targets. The leading proponents of the position are Philip Pettit and Hubert Dreyfus. I reply to Pettit swiftly, and address Dreyfus' view in detail.

Pettit's pessimism is based on a false premise. He presumes that trust seeks to be well grounded and so requires evidence for trustworthiness. Central to this assessment, he proposes, is the evidence of 'face, frame and file'. Focus on the evidence of face. This is 'available to me as I see and get cued - no doubt at subpersonal as well as personal levels of awareness - to the expressions, the gestures, the words, the looks of people: in a phrase, their bodily presence' (2004: 118). Pettit concludes: because the Internet cannot support the evidence required for a rational assessment of trustworthiness, so rational trust cannot be digitally mediated. Rational reliance, perhaps; but not the interactive, motivebased relationship of trust, in which I adopt reactive attitudes to the other (Pettit 1995). But, in reply to Pettit, as degrees of someone's presence are increasingly replicated in acts of mediated interaction, both bodily and audibly, the sub-personal components of communication will be gradually restored. Better technology makes more of this implicit level of communication available. In restoring the evidence of face, telepresent communication renders false one of his premises and enables evidentially constrained, mediated trust. ${ }^{11}$

Dreyfus' pessimism is more fundamental. It is based on a constitutive feature of telepresent technology, namely those communicating not being physically co-present to each other. He claims that we 'sense a crucial difference' between those we can touch and those we cannot, and thus that trust requires touch (2009: 67). He speculates that our sense of trust must 'draw on the sense of security and well-being each of us presumably experienced as babies in our caretaker's arms'. His argument against the possibility of trust supported by telepresence then proceeds as follows.

Of course, there are many kinds of trust, and the trust that we have that our mail carrier will deliver our mail does not require looking her in the eye or shaking her hand. [A] The kind of trust that requires such body contact is our trust that someone will act sympathetically to our interest even when so doing might go against his or her own.

[B] So, it seems that to trust someone you have to make yourself vulnerable to him or her and they have to be vulnerable to you. [C] Part of trust is based on the experience that the other does not take advantage of one's vulnerability. [D] You have to be in the same room with someone who could physically hurt or publicly humiliate you and observe that they do not do so, in order to trust them and make yourself vulnerable to them in other ways. (2009: 69; [A]-[D] inserted for ease of subsequent reference)

Despite his assertion that he is 'quite sure' that telehugs will not do for people what hugs do, the other hedge terms in his discussion belie the confidence. 'Perhaps', 'I doubt', 'could', 'may well', 'it seems' - all these ensure that his position is in the main one of suggested possibilities, rather than asserted facts awaiting confirmation or falsification. No doubt that this is appropriate; the future is uncertain. Yet he does make the unqualified claim, [A], that there is a kind of trust that requires embodied contact, the

\footnotetext{
${ }^{11}$ This is not a strike against Pettit. 'I cannot say that telepresence will always remain constrained in these ways. Perhaps lurking out there in the future of our species is an arrangement under which telepresence can assume firmer, more assuring forms and serve to mediate rational trust' (2004: 12).
} 
trust 'that someone will act sympathetically to our interest even when so doing might go against his or her own'. If correct, then telepresence cannot support this trust- trust which, given what is at stake, may be presumed to be evidentially constrained. Is this so?

I see no reason to think that telepresence cannot support such trust, and the argument given for the key conclusion, [A], is unsound. I assume that the trust of [B] is equivalent to that of $[\mathrm{A}]$. Grant, further, that $[\mathrm{C}]$ follows from $[\mathrm{B}]$ : that to be practically rational in making yourself substantially vulnerable to someone, you need to have experience of them not taking advantage of your vulnerability in other ways. Nevertheless, [D] does not follow from [C]. It is false that you have to be in the same room as someone to have experience of them not taking advantage of you. There is perhaps a debate about how vulnerable you can be to being physically hurt by someone who is not physically present, but there is no reason in principle why someone could not swing a punch with a telerobotic arm. But in such a scenario, you would presumably retain sufficient control over telepresent contact to be able to end it at will, and so you retain a degree of invulnerability. Nonetheless, it is unquestionable that one does not need to be physically present in order to be humiliated publicly. This happens routinely on Facebook. ${ }^{12}$ Nor does it require the presence of a third party to be humiliated; I may be humiliated by my boss's character assassination of me in my end of year review, even though no others are present. If vulnerability is required for particularly important kinds of trust, Dreyfus has given no reason to suppose that one is invulnerable when communicating telepresently.

Even so, it may be objected that there is something Dreyfus has hit on, which bears on the kinds of trust that telepresent communication is well suited for. There are undoubtedly some relationships, which involve particular kinds of trust, which I would not want to conduct without significant periods of embodied co-presence. Examples are being married and raising children. No doubt, this view is widely shared; intimacy and trust in healthy relationships of this sort is generally sustained only by living in shared physical space and through physical contact. But the fact that $I$ find it difficult to imagine how I could enjoy conducting such relationships in a disembodied way is no necessary guide to how others might view the matter, nor to its possibility. Sometimes people fall in love with and marry prisoners whom they have met only after they were incarcerated, and who will never be released. The relationship is one essentially conducted at a distance, with occasional visits and physical contact restricted to holding hands under the eyes of prison guards. If I cannot think of ways in which people might establish such forms of trust through telepresent communication, this is a failure of imagination on my part. As the technological environment changes, so people adapt their relationships to the changed context. How people might do this is opaque.

So distinguish between two possible conclusions. Taking account of his disavowals of certainty, Dreyfus's thesis is well summarised as follows: probably, telepresence cannot support certain important forms of trust. The claim of impossibility is qualified epistemically, in the way that one might tentatively endorse the modal ontological argument for God's existence. It is a modal claim that is at stake, however, because he claims a conceptual relation between the disembodied nature of telepresent communication and the impossibility of important kinds of trust, including that which is evidentially constrained. I have shown the grounds for this supposed conceptual relation to be inadequate, and it is unclear to me what alternatives there may be. At the least, the burden of proof is on those who

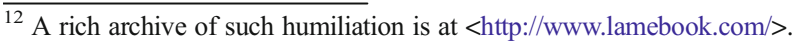


would assert such a relation. In contrast, while I accept that telepresent forms of communication are not conducive to establishing and sustaining important forms of trust, the relation is a contingent one. If so, the following different conclusion is warranted: probably, most people will not establish and sustain important forms of trust through telepresence. The difference is subtle but significant. One implication is that different kinds of reason must be given in support. Dreyfus argues a priori; I shall argue a posteriori.

\section{The Experience of Telepresence}

As noted, telepresence comes in degrees, with different technologies supporting different degrees of telepresence. Given this, one guide to how greater degrees of telepresence will be experienced in the future is how lesser degrees are experienced now. The guide is, admittedly, not a strong one, but it is the best we have. As such, I examine one such study in detail.

A device that improves the quality of telepresence from a landline telephone is video on a mobile: FaceTime or Skype from a smartphone, essentially. A diary study of how people experienced the phones shows how their use was thoroughly shaped by a series of social factors (O'Hara et al. 2009). Part of the value of the study is that it took place when the technology was not widespread, and therefore the forms of social adaptation were evident to users.

A first point from the study is how infrequently the mobile video telephone was used. Over a 5-week period, an average of one video call per person was made every 2 weeks and one received every 3 weeks. The suggestion made by the authors of the study is that the relative infrequency of mobile video telephone calls is in large part not due to any technological limitations. Rather, features of the technology render it ill suited for communication in many situations principally or solely because it would be socially unsuitable to use the phone on those occasions (2009: 305). It turns out that the key advantage of the phone - the way it allows people to see each other and the world in their respective locations - is also its key disadvantage. Video telepresence is experienced as revealing. There was a positive side to this, but perhaps more interestingly, also a negative. This should be no surprise, on reflection, for having things revealed is very often what we do not want to happen.

The mobile video telephone forced those talking to think about how they looked. A video call suddenly creates a situation where another person is looking at you, and how you look may be socially significant. One participant reported:

I used it in conversation with this French girl. When she used it for the first time, she'd just got out of bed, she was in her pyjamas, her hair was a mess and she's never used it since... it's too invasive. If I got a video call, half the time I wouldn't use it. It's like having someone walking in your house and saying 'what are you doing?' I don't want that. (2009: 314)

The reasons to avoid video calling reported here are broadly self-protective ones. But it can also be out of concern for others' protection that I do not want them to see me like this. Lying in bed with his girlfriend, one participant chose to make an audio-only call to his parents, for he knew that they tacitly disapproved of the relationship. An audio-only call allowed both parties to avoid the issue, whereas a call with video would have forced unnecessary conflict. The way in which video telepresence reveals where 
the speaker is, and whom they are with, is often something that a user does not want. As such, the person speaking in those instances deliberately chose forms of communication that did not reveal too much. Evidently, it is possible to have too much telepresence.

Managing disagreement within a relationship without causing conflict is a wellestablished reason for 'white lies'. One study of why lies are told in everyday life concluded, for instance, that the most frequent reason is that 'other people's feelings matter more... than the truth' (DePaulo et al. 1996: 993). Yet video telepresence makes this harder than audio alone.

You can't really lie can you? You don't want to lie do you but you know... Say if I call Shaun and say 'I'm at so and so and I'll be there in 10 minutes' and really you're somewhere else and you're going to be 20 minutes. You can't do that with a video call. (2009: 315)

Video telepresence can make it harder to sustain a relationship when hiding some of the truth, or lying would smooth things over. Similarly, video telepresence has consequences for those who are physically near to the caller. It reveals whom the caller is with. With a telephone call, these 'co-present others' have a choice about whether to participate or not. But with a video call that choice was removed. The video call also risks relaying images of bystanders who have no connection with the call being made, and of displaying images to those same bystanders, in much the way that newspapers are displayed to others in the train carriage and are read over the shoulder. This has consequences for both parties. For the bystander, they are exposed to a conversation they may well rather not be part of. For the caller, the telepresent communication is not only overheard but also 'over-watched' by others, with all the effects this has on how one relates to another when both know that the conversation is no longer private.

In contrast, the distinctive features of the mobile video telephone were particularly valuable when the relationship was one that prized intimacy. The ability of video to reveal becomes an advantage in precisely these situations. 'I like the idea of being able to see my husband when he's away before I go to sleep' (2009: 307). Similar observations were made by those using it to call children or speak to extended family members. By revealing the physical person, the mobile video telephone reinforced the bonds of intimacy that already bound the callers. Another participant summarised the positive dimensions of telepresent communication:

The video thing becomes a bit more of a special occasion thing because it sort of takes a bit more to achieve it. ... It's not an everyday use of the phone. (2009: 307)

The study allows some lessons specific to telepresent communication to be drawn. Telepresent communication is experienced as 'invasive', or more modestly, as revealing. This explains why it is relatively infrequently used (the result is corroborated by Hirsh et al. 2005). Because telepresence comes in degrees, a modest inference from this result is that, as technologies of communication develop, a basic correlation will be observed: the more telepresence a technology of communication offers, the more that technology is experienced as revealing. There are some situations where this will be entirely welcome, such as in the context of relationships where revelation supports intimacy, or indeed accountability. But there are other relationships where this degree of revelation will be unwelcome. 


\section{A Speech-Act Theory of Mediated Communication}

The act of communicating telepresently — or trying to communicate telepresently, by initiating contact - is socially consequential. It is appropriate in some situations and inappropriate in others. The nature of the pre-existing relationship between people is one factor that determines the choice. Another factor is the purpose of the call. Alongside what is said, conversations may have a purpose, often many. Telepresent communication was found to be a felicitous means of communication for some sorts of conversations, but not for others. 'You don't use it if you have something important to talk about' (O'Hara et al. 2009: 306). The decision to communicate telepresently, rather than through some other means, in turn says something about both of these factors. The fact that telepresent communication is chosen as the way to communicate can itself play a role in confirming or contesting the nature of the existing social relationship between those talking. If the relationship is such that there is expectation of a certain distance between those speaking, the decision to communicate telepresently says that something unusual is going on.

Thomas Nagel argues that a distinction between public and private domains of life serves to allow things that would cause unnecessary conflict to remain unacknowledged, even if not actively denied, and thereby to create space for what he calls 'the inner fantasies and obsessions and personal relations of individuals', which constitute part of human flourishing (Nagel 1998: 18). With the arrival of the new technology of mobile video telephones, users in the diary study were confronted with having to re-negotiate this boundary, by working out how to use their telephone in a way that respected others' privacy. Insofar as mobile video telephony is one technology along a spectrum of possible technologies that facilitate telepresence, there is reason to think that this same dynamic will be replayed as new technologies are fielded. There are reasons for communicating telepresently, rather than a different way. This is the 'why' of telepresence.

The reports of how telepresent communication was experienced, however, also warrant some more general conclusions about the nature of communication technologies. We now have a potpourri of different technologies of communication, each of which has different properties - whether it be synchronous or asynchronous, with differing expectations of how long it will take for the 'speech' to reach the intended recipient; handwritten or typed; electronic or paper; audio, visual, or text; with varying degrees of assurance that the communique will reach only the intended recipient. Given the kind of creature we are, and the kinds of life we lead, these technologies of communication are apt for particular communicative purposes: their properties and our capacities as agents jointly make salient particular 'action possibilities'. As Donald Norman uses the term, these technologies have 'affordances' (1998: 9-11). Door handles saliently invite — or 'afford'—pulling, and doorplates afford pushing. Different technologies of communication afford specific communicative purposes.

The impact on the distinction between public and private noted by Nagel is one important way in which technologies of communication have, by the very way they are built, a social significance. But it is not the only one. A different technology of communication that carries a different social significance, for instance, is the letter. Letters that are handwritten in ink, for instance, have the particular property that mistakes cannot easily be corrected without the time consuming process of starting again, or the clumsy and evident use of correction fluid or the messiness of striking through. This tends to ensure that the writer thinks carefully about what they say before they commit pen to paper. In part due to this very specific feature of the 
technology, letters are a felicitous choice when the purpose of the communicative act is one of great significance. The 'weight' of the act of writing a letter makes letters well suited for declarations of love. Just as there is a why of telepresence, so there is a why for each media of communication.

A consequence is that volumes of information do not always equal better communication. This claim is contradicted by the second position rebutted by this paper, influential especially among those computer scientists who build the technology. Media Richness Theory claims that people process information to reduce uncertainty and overcome equivocality (the problem of conflicting interpretations of information). Therefore media that offer a greater degree of 'richness' - viz a greater degree of telepresence - are better for communication than those which do not. There is a linear relationship between the volume of mediated information and the quality of communication. The theory predicts that people use less rich forms of communication only because they are forced to (the sources of the theory are Daft and Lengel 1986; Daft et al. 1987). This endearingly mechanistic picture of communication technology is belied by the reports from the study. No doubt, people do sometimes process information to reduce uncertainty and overcome equivocality, but often enough we want our communication to preserve uncertainty. One of the lessons from the experience of telepresence is that sometimes, less is more. That is, less information serves some communicative purposes better than more would.

This supports the further point: although the direction in which telepresent technologies are being developed is towards transparent simulation of face-to-face contact, the fact that existing such technologies fall short of this does not mean they fail to support effective communication. Indeed, in one study, distributed work groups performed worse on objective measures of task completion when they had high fidelity video and audio communication than a group working with low band conditions (Matarazzo and Sellen 2000). Rather, when people use such technologies for a prolonged period of time, new habits and ways of interacting through that specific medium develop (Dourish et al. 1996; for the parallel point with regard to multi-user virtual environments, which enable a virtual form of telepresence, see Schroeder 2011: 181-6). Telepresent communication that is unlike face-to-face communication does not 'fall short' of some benchmark; it is just a different way of communicating. I now step up a theoretical level to provide a more general explanation of how specific features of a technology come to have social significance.

In How to do things with words, Austin argued that there was a third type of speech act that had been overlooked. The locutionary act is the type of utterance, whether assertoric statement, question, promise, warning, command and so on. The perlocutionary act is the 'consequential effect' that results from what someone has said. My saying to you 'You can't do that' may have the effect of stopping you from doing that, bringing you to your senses or annoying you (1962: 102). The overlooked aspect of speech acts is the illocutionary act, which is the speaker's intention in performing the locutionary act. ${ }^{13}$ To perform a locutionary act is, invariably, also to perform an illocutionary act. When I say you can't do that, whether you are outraged at my impertinence or grateful for my sympathy will likely depend on whether you understand me to be commanding you with an authority I lack, or advising you on the best course of action given my experience of these things. It is not sentences only that

\footnotetext{
13 'Our interest in these lectures is essentially to fasten on the second, illocutionary act and contrast it with the other two. There is a constant tendency in philosophy to elide this in favour of one or other of the other two' (1962: 103).
} 
may constitute illocutionary acts. Conversations may too. The point of a conversation, for instance, may have been to encourage someone, or forewarn them. Once the hearer has determined the speaker's illocutionary act, this is the basis for the perlocutionary effect.

My contention is that part of how an illocutionary act is performed is the choice of the media of communication. This is because there are reasons for why someone chooses to communicate telepresently, for example as opposed to another means of mediated contact. It is Christmas Day, and the family gathers round the laptop for a Skype call with the son who is overseas. The locutionary acts performed by the family consist in questions, statements, jokes and expressions of thanks for presents. The illocutionary act is an affirmation of familial intimacy. Because this was the purpose, a Skype call was chosen, rather than an instant messenger exchange. The choice of the media of communication is part of how something is said. Or consider the view that dumping someone by text is a cruel and cowardly way to do something that is seldom pleasant. It is not that dumping someone is wrong. But there is something about doing it by text that is particularly bad. The illocutionary act is one of snubbing, or disrespecting.

Given that a specific feature of telepresent communication is its being experienced as revealing, there is a further connection with how telepresent communication can build trust, and specifically, evidentially constrained trust. Insofar as the choice to communicate telepresently is socially significant, this choice may be felicitous or infelicitous in building trust within the relationship. Telepresent communication builds trust between those who are already intimate, because of the continued willingness to reveal oneself (It may also be a tool for control, when it takes place within a hierarchical social context; in this case, trust is unlikely to come into it.). Equally, to seek telepresent communication when the relationship does not support it may do more to break trust than build it. I do not deny that telepresent communication may offer richer cues to help work out whether a person is trustworthy or not in a particular instance. Job interviews may be an example. But I suggest that this is not the most important way in which telepresent communication affects trust practices. It is whether or not telepresence is the appropriate medium for communication, given the purposes of the person who gets in touch and the social context of that communication. This latter shapes whether or not telepresence is a felicitous way of building trust within this particular relationship. As such, the decision to initiate (and accept) communication with high degrees of telepresence constitutes evidence for a person's understanding of the social context of the encounter, evidence that shapes how one interprets and understands the actual content of the ensuing conversation and judgements of the other's trustworthiness. Consequently, it shapes when one's trust is rational.

\section{Conclusion}

There are some striking exceptions to the claim that people do not wish to reveal themselves to others. Jennifer was one of the early adopters of webcams. What was unusual about her online behaviour was that her webcam was in her bedroom and turned on at all times, broadcasting to whoever wanted to watch what she was doing at the time: getting changed, cutting her toenails, reading or having sex. She kept the webcam on for 4 years. ${ }^{14}$ Jennifer

\footnotetext{
${ }^{14}$ Things went badly wrong when Jennifer slept with the fiancé of one of her friends, who watched the infidelity live through the webcam. The story is told by Solove (2007: 71).
} 
appears genuinely not to have cared what others saw her doing; her story is interesting because it is so unusual. Nevertheless, there are two important ways in which her behaviour respected social boundaries. She did not force or put any pressure on others to witness her self-exposure. Whether someone chose to watch what her webcam revealed was entirely up to them; they had made an active choice to go to the website. And the gaze was one way; she did not ask others to reveal themselves to her in the way that she was revealed to them. Telepresent communication is different in both these respects, for someone who initiates a telepresent 'call' is explicitly asking that the receiver permit the initiator to see the receiver and their world. Moreover, the initiator is also asking that the receiver accept the initiator's self-exposure. The degree of revelation and intrusion involved is such that it is inappropriate to ask it of a stranger unless there is a very good reason to do so.

Similarly exceptional, the website $<\mathrm{http}: / /$ chatroulette.com/ $>$ enables you to connect to strangers through your webcam, allocated on a random basis. The fact that a dedicated forum has to be provided where one's presence implies consent is oblique testimony to the power of the convention against contacting strangers telepresently. It is striking and interesting that one should be put in touch telepresently with a stranger, precisely because it is so unusual and runs so counter to normal practice. Moreover, the reason why most people engage in chat roulette seems not to be because they want to build relationships and establish trust. It is for entertainment. A blogger comments:

This appears to be the place where all the freaks trawling 4chan ... have migrated their insanity. And it's insanely addictive - basically like a slot machine where instead of cherries, you're hoping for the strangest that humanity has to offer. Self-published entertainment has officially moved into territory I can barely comprehend. ${ }^{15}$

An implication from this speech-act theory of digitally mediated communication concerns the limitations on the kinds of trust we will be likely be able to generate online. Some of the important kinds of communicative encounter that people want on the Internet - the ones where trust is important but not taken for granted, as between pure virtuals - are not well facilitated by the sorts of encounter that Skype and other forms of telepresent communication offer. It is socially inappropriate to ask a journalist for coffee after reading a story that you wish to verify. It is inappropriate in the same way to initiate a Skype call with someone whom you have never met. It is not that there are no circumstances where it would make sense either to ask that journalist for coffee or to Skype someone whom you have never met, and in which that face to face conversation may be an apt way of building trust. It is just that it is usually not the case. Telepresence may be good for maintaining some kinds of trust. It is less suited for building it. ${ }^{16}$

\footnotetext{
${ }^{15}$ The website <http://www.4chan.org/> is one of the more notorious sites for sheer bile. Quoted from $<$ http:/web.archive.org/web/20130203085608/http:/www.fastcompany.com/1528888/welcome-weirdestnew-internet-pastime-chat-roulette $>$. For examples of the kind of encounter that chat-roulette encourages, see <http://www.buzzfeed.com/awesomer/the-24-best-chat-roulette-screenshots-nsfw>. (NB. "not safe for work'- 'NSFW', although this page is more alarming than obscene.)

${ }^{16}$ For comments, criticism and discussion, I am grateful to Tim Crane, Richard Harper, Jeroen van den Hoven, Nik Kirby, Hannah Maslen, Alex Oliver, two anonymous referees and audiences in Oxford and Milwaukee. All URLs were verified as accurate on 21 Jan. 2016.
} 
Open Access This article is distributed under the terms of the Creative Commons Attribution 4.0 International License (http://creativecommons.org/licenses/by/4.0/), which permits unrestricted use, distribution, and reproduction in any medium, provided you give appropriate credit to the original author(s) and the source, provide a link to the Creative Commons license, and indicate if changes were made.

\section{References}

Adler, J. E. (2002). Belief's own ethics. Cambridge, MA: MIT Press.

Austin, J. L. (1962). How to do things with words. Oxford: Clarendon Press.

Author. 2012a. Title. Journal

Author. 2012b. Title. Journal

Author. Forthcoming. Title. In Philosophical essays on trust, ed. P. Faulkner and T. Simpson. Oxford: Oxford University Press

Baier, A. C. (1994). Moral prejudices: essays on ethics. Cambridge, MA: Harvard University Press.

Baker, J. (1987). Trust and rationality. Pacific Philosophical Quarterly, 68, 1-13.

Daft, R. L., \& Lengel, R. H. (1986). Organizational information requirements, media richness and structural design. Management Science, 32, 554-571.

Daft, R. L., Lengel, R. H., \& Trevino, L. K. (1987). Message equivocality, media selection, and manager performance: implications for information systems. MIS Quarterly, 11, 355-366.

DePaulo, B. M., Kashy, D. A., Kirkendol, S. E., Wyer, M. M., \& Epstein, J. A. (1996). Lying in everyday life. Journal of Personality and Social Psychology, 70, 979-997.

Domenicucci, J., \& Holton, R. Forthcoming. Trust as a two-place relation. In P. Faulkner \& T. Simpson (Eds.), Philosophical essays on trust. Oxford: Oxford University Press

Dourish, P., Adler, A., Bellotti, V., \& Henderson, A. (1996). Your place or mine? Learning from long-term use of audio-video communication. Computer-Supported Cooperative Work, 5, 33-62.

Dreyfus, H. L. (2001). On the Internet. London: Routledge.

Dreyfus, H. L. (2009). On the Internet (2nd ed.). London: Routledge.

Faulkner, P. (2007). On telling and trusting. Mind, 116, 875-902.

Faulkner, P. (2015). The attitude of trust is basic. Analysis, 75, 424-429.

Floridi, L. (2005). Telepresence: from epistemic failure to successful observability. In L. Magnani \& R. Dossena (Eds.), Computing, philosophy and cognition (pp. 37-56). London: College Publications.

Goldberg, K. (Ed.) (2000). The robot in the garden: telerobotics and telepistemology in the age of the internet. Cambridge, MA: MIT Press.

Good, D. (1988). Individuals, interpersonal relations, and trust. In D. Gambetta (Ed.), Trust: making and breaking cooperative relations (pp. 31-48). Oxford: Basil Blackwell.

Harper, R. 2009. From telepresence to human absence - the pragmatic construction of the human in communications systems research. Proceedings of the 23rd British HCI Group Annual Conference on People and Computers, 73-82

Harper, R. (2010). Texture: human expression in the age of communications overload. Cambridge, MA: MIT Press.

Harrison, S. (Ed.) (2009). Media space: 20+ years of mediated life. London: Springer-Verlag.

Hieronymi, P. (2008). The reasons of trust. Australasian Journal of Philosophy, 86, 213-236.

Hirsh, S., Abigail S., \& Nancy B. (2005). Why HP people do and don’t use videoconferencing systems. $H P$ Technical Report HPL-2004-140(R.1). Available at: <http://research.microsoft. com/enus/um/people/asellen/publications/why\%20hp\%20people\%2004.pdf>.

Holton, R. (1994). Deciding to trust, coming to believe. Australasian Journal of Philosophy, 72, 63-76.

Hugo, V. (1862). Les Misérables. Paris: A. Lacroix, Verboeckhoven \& Cie.

Hurka, T. (2001). Virtue, vice and value. Oxford: Oxford University Press.

Kelly, T. (2008). Disagreement, dogmatism and belief polarization. Journal of Philosophy, 105, 611-634.

Lombard, M., \& Jones, M. T. (2006). Defining presence. In M. Lombard, F. Biocca, J. Freeman, W. Ijsselsteijn, \& R. J. Schaevitz (Eds.), Immersed in media: telepresence theory, measurement \& technology (pp. 13-34). Basel: Springer.

Marušić, B. (2015). Evidence and agency. Oxford: Oxford University Press.

Matarazzo, G., \& Sellen, A. J. (2000). The role of video in work at a distance: addition or distraction? Behaviour and Information Technology, 19, 339-348.

McGeer, V. (2008). Trust, hope and empowerment. Australasian Journal of Philosophy, 86, 237-254. 
McMyler, B. (2011). Testimony, trust, and authority. Oxford: Oxford University Press.

Minsky, M. (1980). Telepresence. OMNI Magazine, 2, 45-52.

Moran, R. (2006). Getting told and being believed. In J. Lackey \& E. Sosa (Eds.), The epistemology of testimony (pp. 272-306). Oxford: Oxford University Press.

Nagel, T. (1998). Concealment and exposure. Philosophy and Public Affairs, 27, 3-30.

Norman, D. A. (1998). The design of everyday things. Cambridge, MA: MIT Press.

O'Hara, K., Black, A., \& Lipson, M. (2009). Media spaces and mobile video telephony. In S. Harrison (Ed.), Media space: 20+ years of mediated life (pp. 303-323). London: Springer-Verlag.

Pettit, P. (1995). The cunning of trust. Philosophy and Public Affairs, 24, 202-225.

Pettit, P. (2004). Trust, reliance and the internet. Analyse und Kritik, 26, 108-121.

Schroeder, R. (2011). Being there together: social interaction in virtual environments. Oxford: Oxford University Press.

Sellen, Abigail J. 1992. Speech patterns in video-mediated conversations. Proceedings of the ACM Conference on Human Factors in Computing Systems CHI'92, 49-59. New York, NY: ACM Press

Sellen, A. J. (1995). Remote conversations: the effects of mediating talk with technology. Human-Computer Interaction, 10, 401-444.

Simpson, T. W. 2012a. What is Trust? Pacific Philosophical Quarterly, 93, 550-69

Simpson, T. W. 2012b. Testimony and Sincerity. Ratio, 25, 79-92

Simpson, T. W. Forthcoming. Trust and Evidence. In P. Faulkner \& T. Simpson (Eds.), The Philosophy of Trust. Oxford: Oxford University Press

Solove, D. J. (2007). The future of reputation: gossip, rumour and privacy on the Internet. New Haven, CT: Yale University Press.

Solove, D. J. (2007). The future of reputation: gossip, rumour and privacy on the Internet. New Haven, CT: Yale University Press.

Stroud, S. (2006). Epistemic partiality in friendship. Ethics, 116, 498-524. 